\begin{tabular}{|c|c|}
\hline & $\begin{array}{l}\text { International Journal of Trend in Scientific } \\
\text { Research and Development (IJTSRD) }\end{array}$ \\
\hline 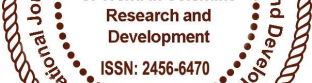 & International Open Access Journal \\
\hline 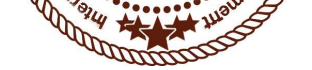 & ISSN No: 2456 - 6470 | www.ijtsrd.com | Volume - 2 | Issue - 2 \\
\hline
\end{tabular}

\title{
Design and Analysis of Helical Gear with different Materials by using Pro/E and Ansys
}

\author{
Koodali Srinivasarao \\ M.Tech Student, Department of Mechanical \\ Engineering, Aditya Engineering College \\ Surampalem, Andhra Pradesh, India
}

\author{
A. Sirisha Bhadrakali \\ Assistant Professor, Department of Mechanical \\ Engineering, Aditya Engineering College \\ Surampalem, Andhra Pradesh, India
}

\begin{abstract}
Gear is a power transmitting element among the rotating shafts by means of progressive meeting of projections which is identified as teeth. The purpose of the gear is transmitting torque (power) among rotating shafts when the central distance between the shafts is comparatively less.
\end{abstract}

The main aim of the paper is to Design and Analysis of a helical gear for marine applications, by using empirical formulas and Calculation, from the data to draw a 3D model helical gear by using Pro/Engineer Software and the Structural and Thermal Analysis is done by the Simulation Software (ANSYS).

Structural and thermal analysis is done using two materials Nickel Chromium Molybdenum Alloy Steel and Aluminum Alloy A360. Structural analysis and thermal analysis is done to conform to the Displacement, Von Mises Stress, and thermal properties related nodal temperature, thermal gradient and thermal flux.

Keywords: Displacement, Von Mises stress, Thermal Gradient, Thermal Flux, Pro/E and ANSYS method

\subsection{INTRODUCTION TO GEARS}

A gear is a rotating machine element including a cut tooth, or cogs, which mesh with by resources of a further toothed element in order to transmit torque. Two or more gears operational in meshed are termed a transmit and can create a mechanical benefit during a gear ratio and thus may be measured an uncomplicated machine. Geared can modify the speed, magnitude and direction of a power supply. The common state is meant for a gear to mesh with another gear; still a gear can also mesh a non-rotating gear toothed element, known as rack, thus producing linear motion instead of turning round.

The gears transmit equivalent to the wheels in a pulley. A benefit of gears is to put off slipping by means of gear teeth.

While two gears of uneven number of teeth are mutual a mechanical gain is formed, with both the rotational speeds and the torques of the two gears opposed in an easy correlations

In transmissions which propose multiple gear ratios, such as bicycles and cars, the term gear, as in first gear, submitted to a gear ratio fairly than a real physical gear. The expression is worn to explain similar devices yet when gear ratio is unbroken slightly than separate, or when the device does not really contain any gears, as in as always uneven transmission.

The originated orientation to gears was circa 50 A.D. by Hero of Alexandria, but they influenced back to the Greek mechanics of the Alexandrian educate in the 3rd century $\mathrm{BC}$ and were deeply residential by the Greek polymath Archimedes (287-212 BC). 


\subsection{Thermal Analysis}

A thermal analysis calculates the temperature distribution and related thermal quantities in a system or component. Typical thermal quantities of interest are:

- The temperature distributions

- The amount of heat lost or gained

- Thermal gradients

- Thermal fluxes.
Thermal simulations play an important role in the design of many engineering applications, including internal combustion engines, turbines, heat exchangers, piping systems, and electronic components. In many cases, engineers follow a thermal analysis with a stress analysis to calculate thermal stresses (that is, stresses caused by thermal expansions or contractions).

\subsection{MODEL OF HELICAL GEAR}

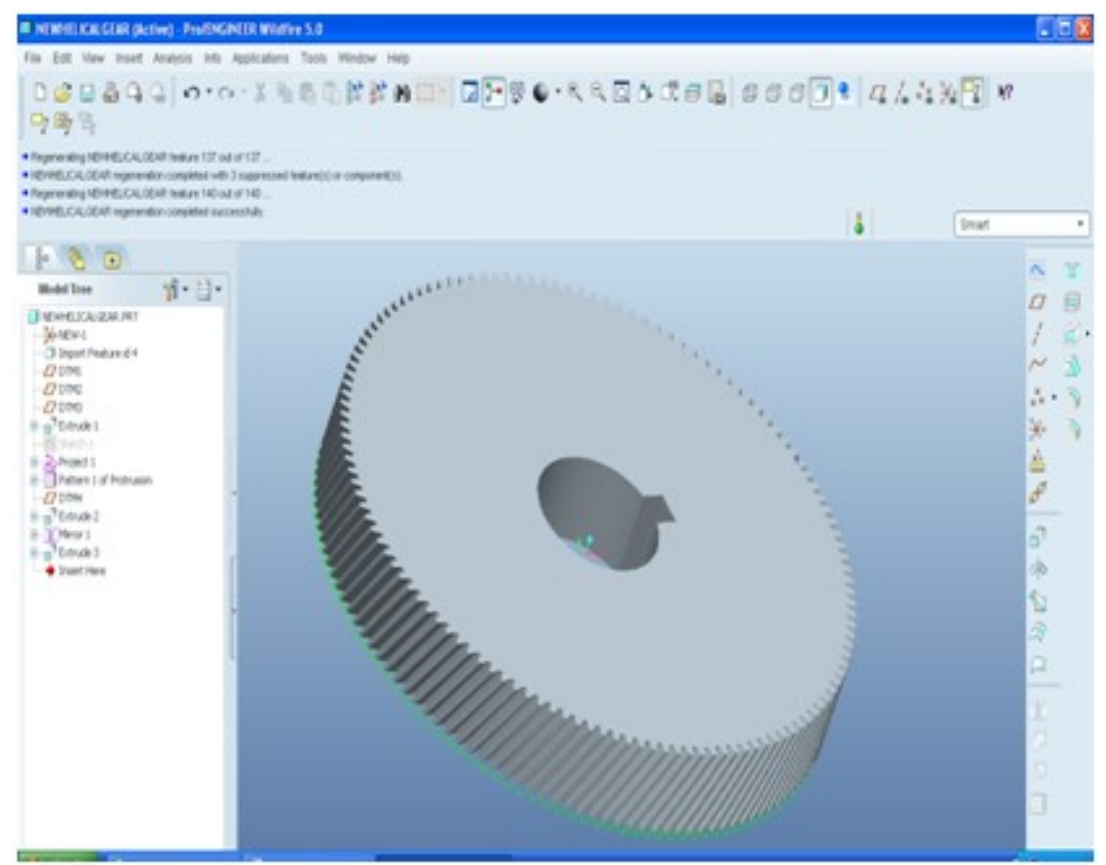

Fig.1.Helical Gear in Pro/E

\subsection{STRUCTURAL ANALYSIS OF HELICAL GEAR USING STEEL}

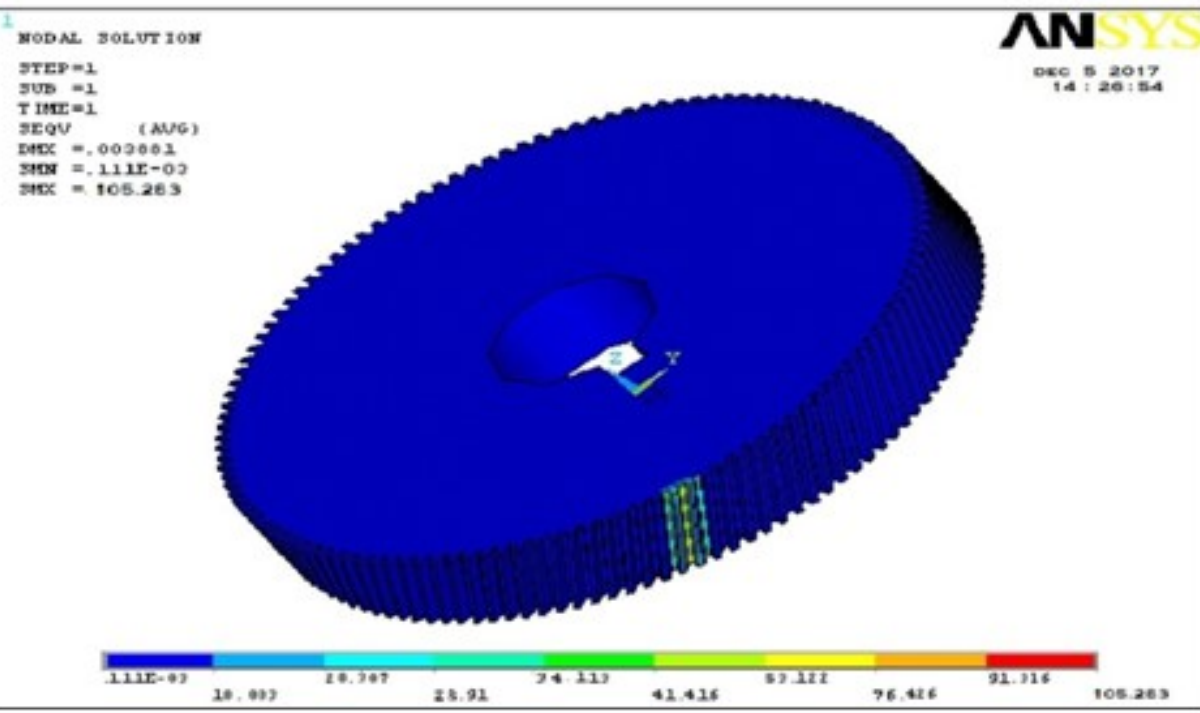

Fig.2. Von Mises Stress for Steel 
International Journal of Trend in Scientific Research and Development (IJTSRD) ISSN: 2456-6470

3.1 Structural Analysis of Helical Gear Using NiCrM Alloy Steel

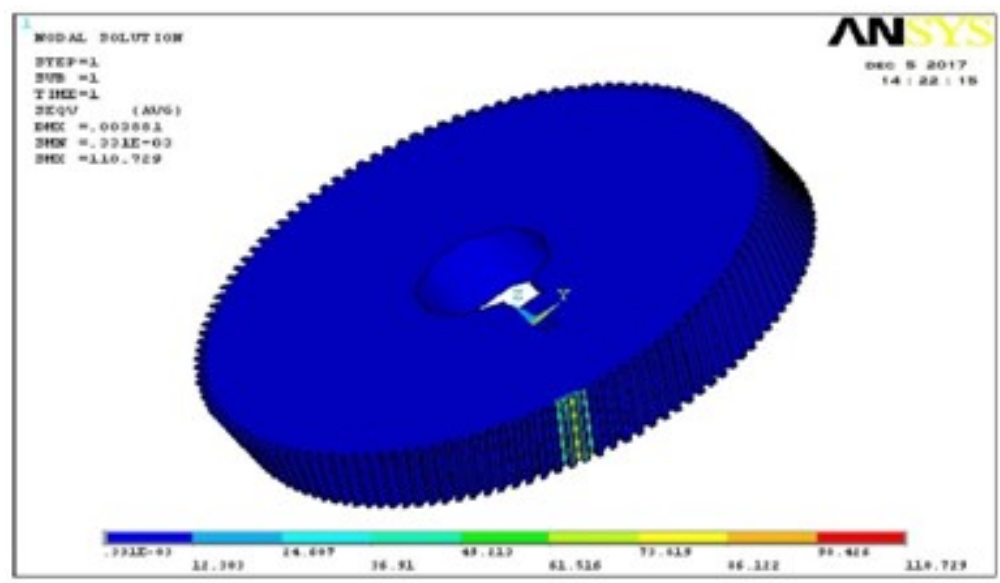

Fig.3. Von Mises Stress for NiCrM Alloy Steel

3.2 Structural Analysis of Helical Gear Using Aluminum Alloy A360

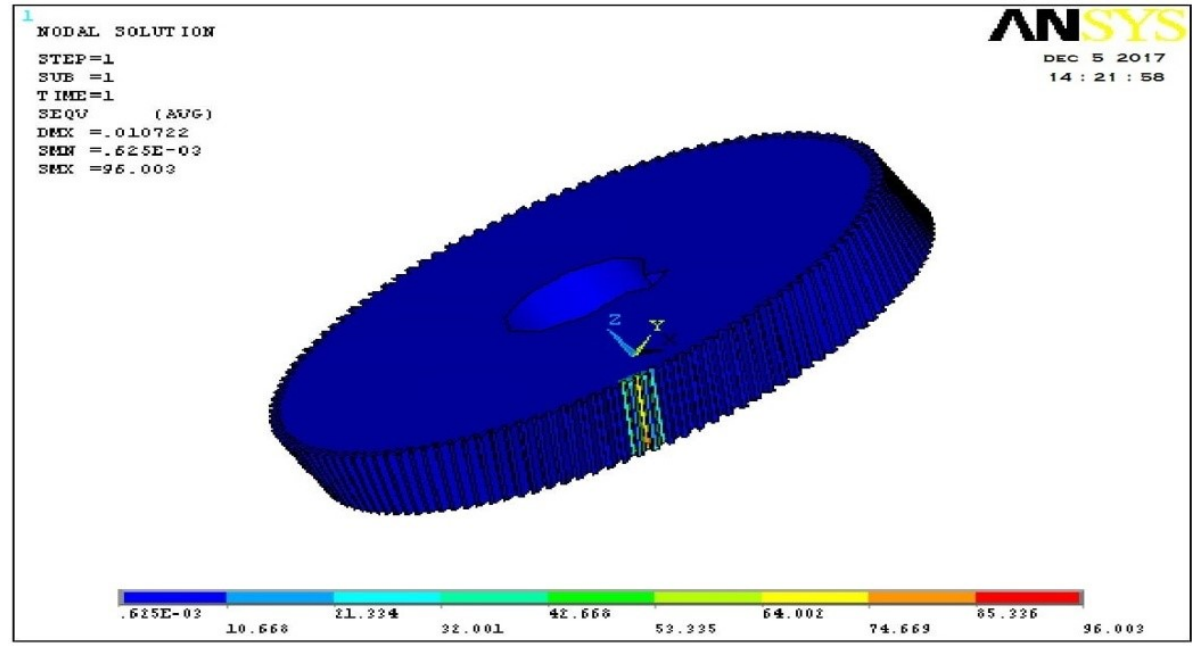

Fig.4 Von Mises Stress for Aluminum Alloy A360

\subsection{THERMAL ANALYSIS OF HELICAL GEAR USING STEEL}

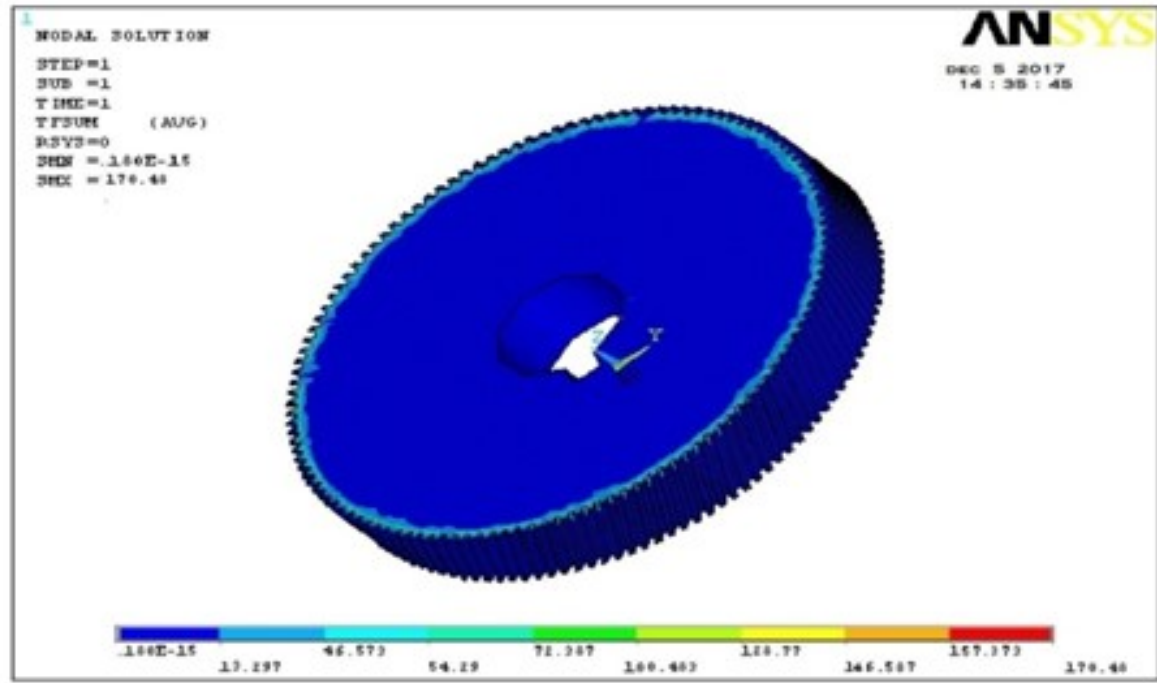

Fig.5 Thermal flux vector sum for Steel 
4.1 Thermal Analysis of Helical Gear using NiCrM Alloy Steel

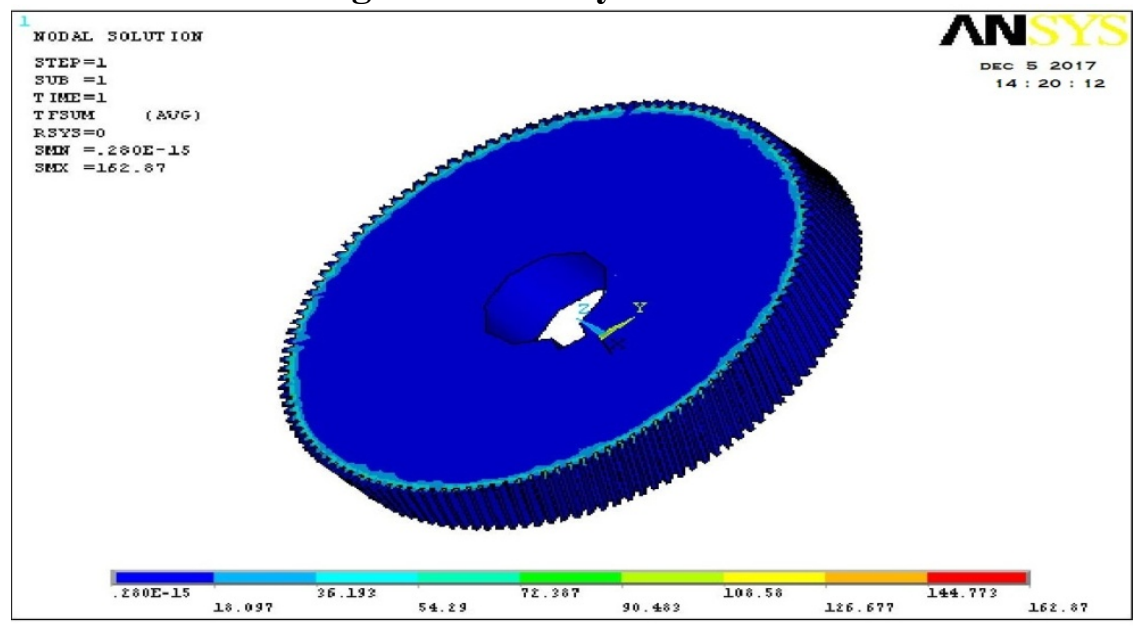

Fig. 6 Thermal flux vector sum for NiCrM Alloy Steel

4.2 Thermal Analysis of Helical Gear using Aluminum Alloy A360

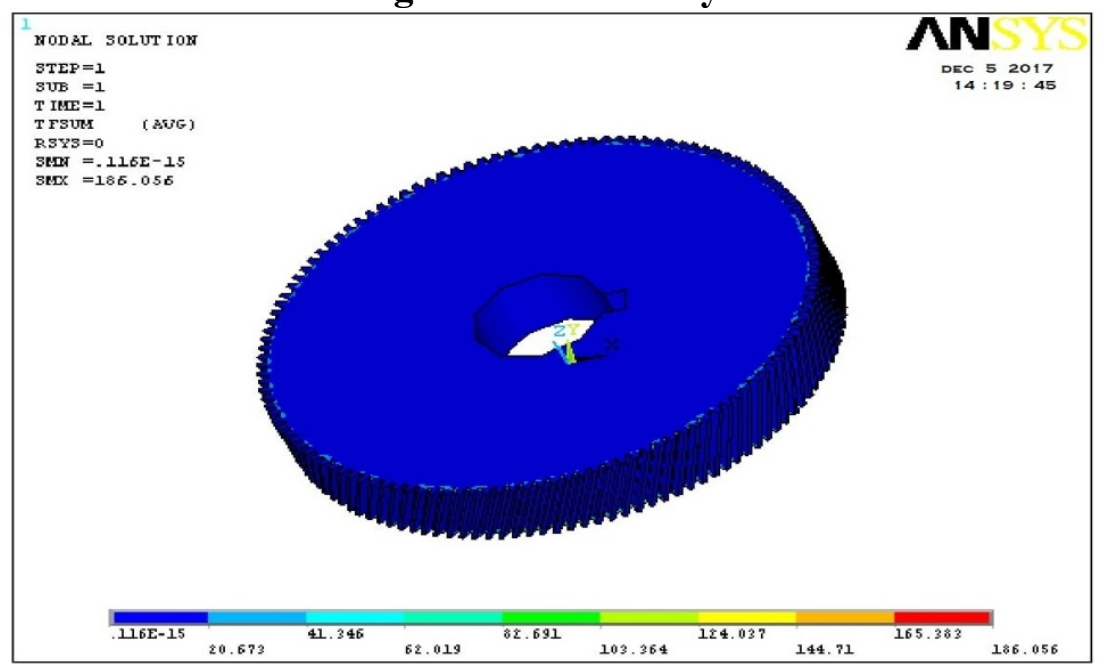

Fig. 7.Thermal flux vector sum for Aluminum Alloy A360

\subsection{RESULTS}

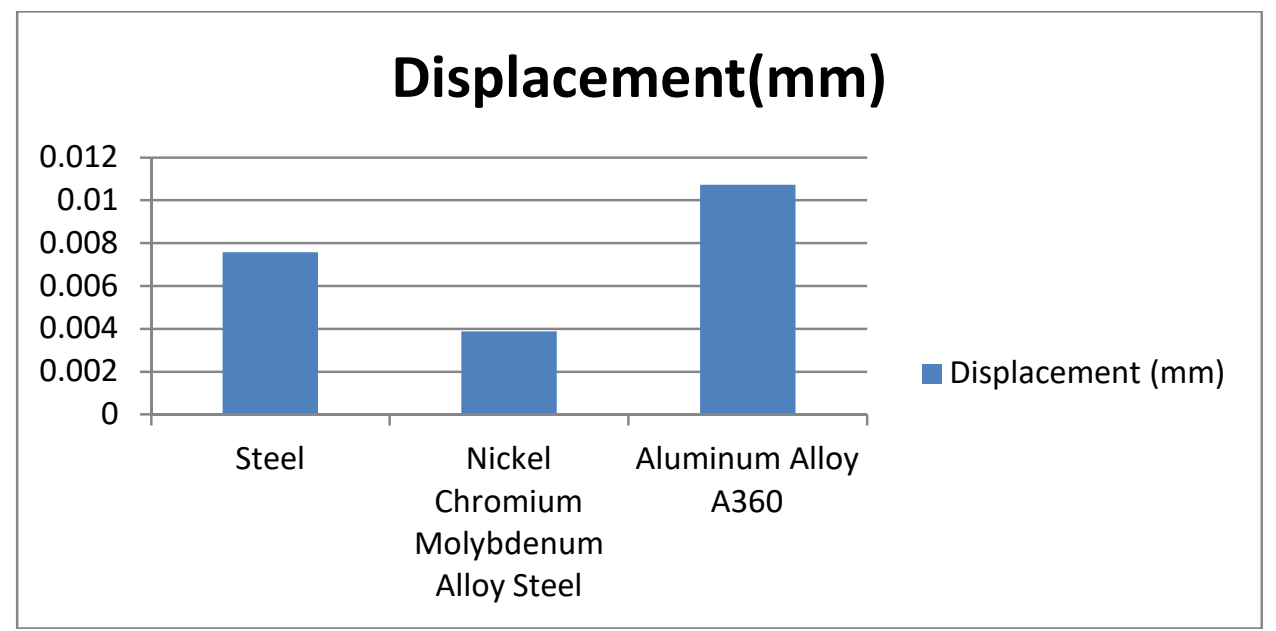

Fig. 8 Displacement for Steel, NiCrM Alloy and Al Alloy A360 


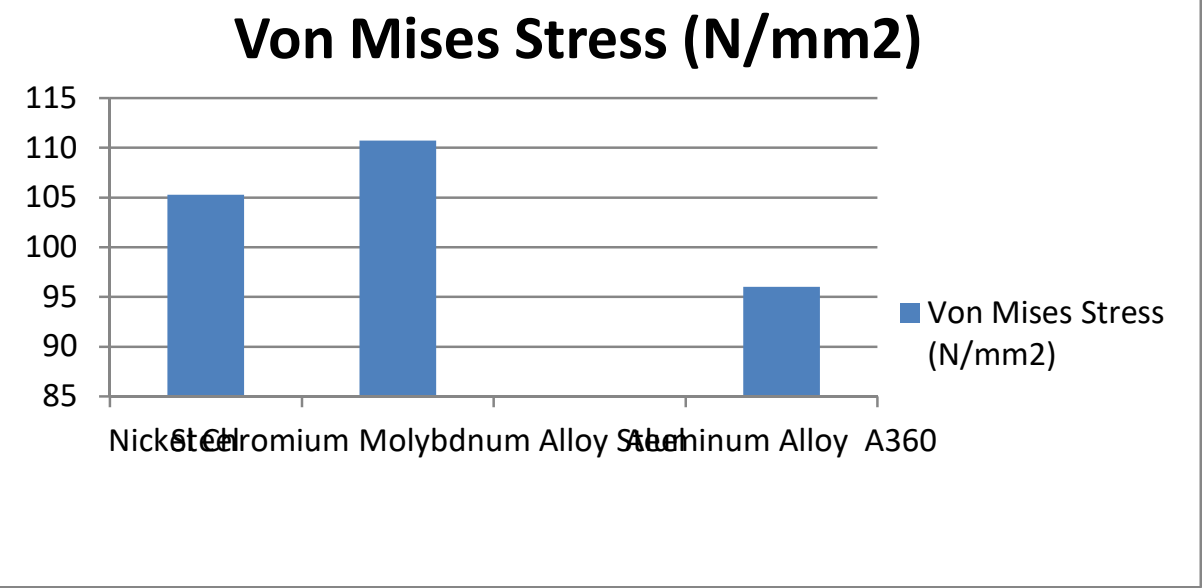

Fig. 9.Von Mises Stress for Steel, NiCrM Alloy and Al Alloy A360

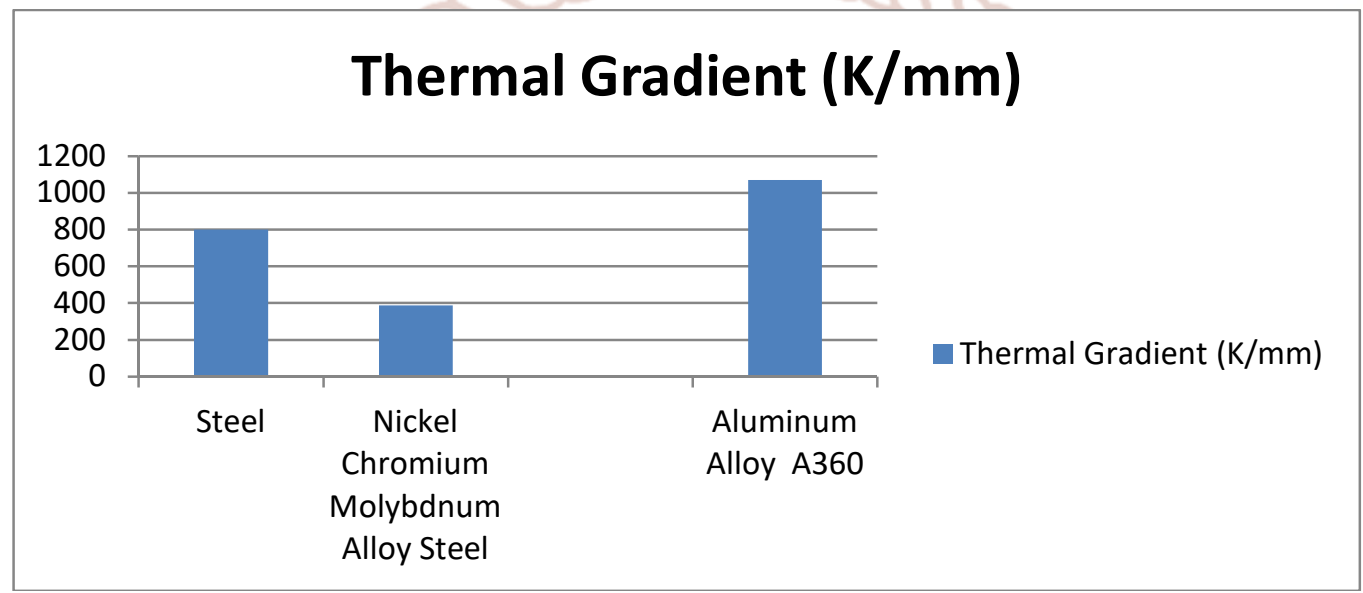

Fig.10. Thermal Gradient for Steel, NiCrM Alloy and Al Alloy A360

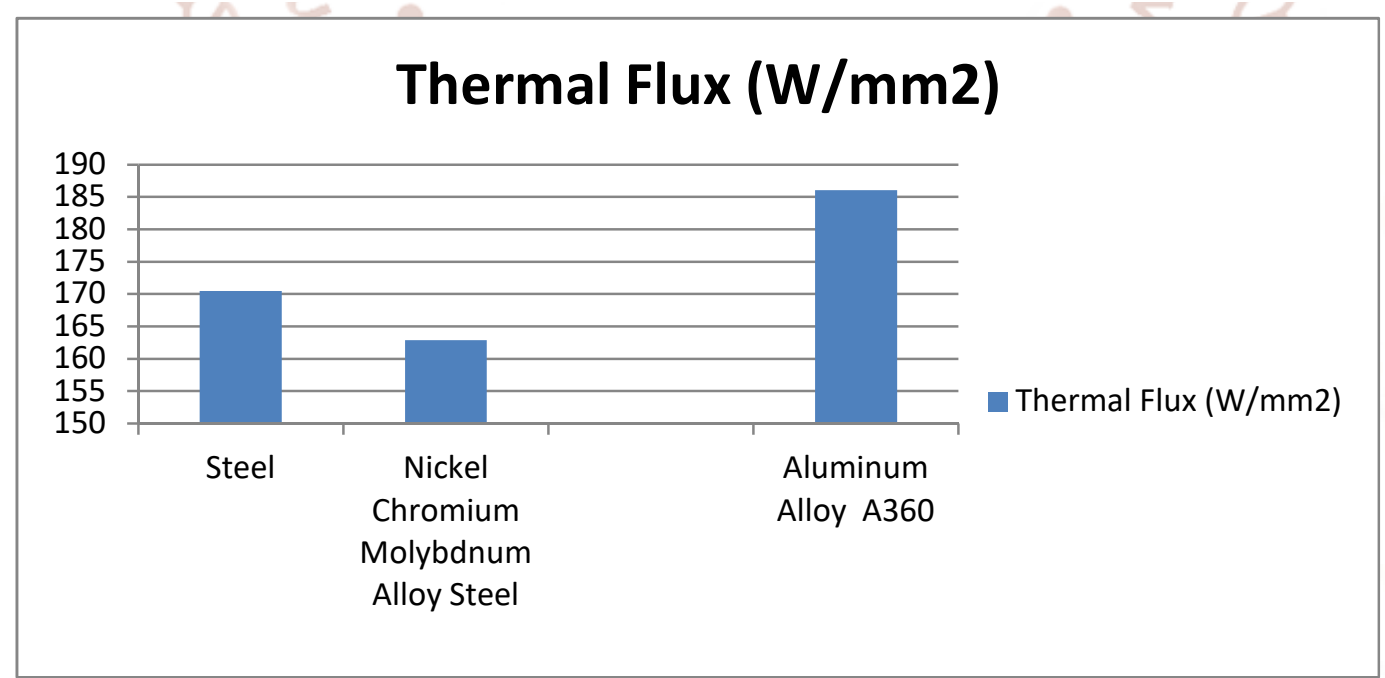

Fig.11 Thermal Flux for Steel, NiCrM Alloy 
International Journal of Trend in Scientific Research and Development (IJTSRD) ISSN: 2456-6470

\begin{tabular}{|c|c|c|c|c|c|}
\hline & $\begin{array}{c}\text { Displace } \\
\text { ment } \\
(\mathrm{mm})\end{array}$ & $\begin{array}{c}\text { Von- } \\
\text { Mises } \\
\text { Stress } \\
\left(\mathbf{N} / \mathbf{m m}^{2}\right)\end{array}$ & $\begin{array}{c}\text { Nodal } \\
\text { Temperatu } \\
\text { re }(\mathbf{K})\end{array}$ & $\begin{array}{c}\text { Therml } \\
\text { Gradie } \\
\text { nt } \\
(\mathrm{K} / \mathrm{mm} \\
)\end{array}$ & $\begin{array}{c}\text { Therma } \\
\text { I Flux } \\
\left(\begin{array}{c}W / m m \\
2\end{array}\right)\end{array}$ \\
\hline Steel & .007581 & 105.263 & 373 & 800.611 & 170.48 \\
\hline $\begin{array}{c}\text { Nickel } \\
\text { Chromium } \\
\text { Molybdenu } \\
\text { m Alloy } \\
\text { Steel } \\
\end{array}$ & 0.003881 & 110.729 & 373 & 387.786 & 162.87 \\
\hline $\begin{array}{c}\text { Aluminu } \\
\text { m Alloy } \\
\text { A360 } \\
\end{array}$ & 0.010722 & 96.003 & 7 & 1069 & 186.056 \\
\hline
\end{tabular}

As per analysis images, we have observed that displacement of three materials, Aluminum alloy A360 is more valves are obtained.

Then von Mises stress are also compared to these three materials, Aluminum alloy A360 is lower than the steel and NiCrM alloy steel.

The thermal gradient and thermal flux are compared with other materials. We have observed Aluminum alloy A360 is more.

Then finally we have observed this is safe working condition because of the von-Mises stress valves are obtained from the analysis is less than the yield stress values.

\subsection{CONCLUSIONS}

$>$ In our project, we have designed a helical gear used in marine applications using theoretical calculations and modeling of helical gear is done in Pro/Engineer.

$>$ We have performed Structural analysis and thermal analysis on helical gear using Steel, NiCrM Alloy Steel and Aluminum alloy A360.

$>$ By observing the analysis results, the stress values obtained are less than their respective yield stresses for three materials. So we can decide that our design is safe under working conditions.

$>$ By comparing the analysis of the three materials,

The thermal Gradient of Aluminum alloy A360 is greater than Steel and Nickel Chromium Molybdenum Alloy Steel

The Von Mises Stress of Aluminum alloy A360 is less than Steel and Nickel Chromium Molybdenum Alloy Steel.
The thermal Gradientof Aluminum alloy A360is greater than Steel and Nickel Chromium Molybdenum Alloy Steel

The thermal flux of Aluminum alloy A360 is more than Steel and Nickel Chromium Molybdenum Alloy Steel.

So we can say that using Aluminum alloy A360 for helical gear is more advantageous than using Steel and Nickel Chromium Molybdenum AlloySteel as per our analysis.

\subsection{REFERENCES}

1) Akinnuli B. O., Ogedengbe T. I. And Oladosu K. O. Published On Computer Aided Design and Drafting of Helical, Journal of Emerging Trends in Engineering and Applied Sciences (JETEAS) 3(6): 959-968, Scholar link Research Institute Journals, 2012 (ISSN: 2141-7016).

2) B. Venkatesh, V. Kamala and A.M.K. Prasad Paper Published On Design, Modelling and Manufacturing of Helical Gear IJAE RESEARCH, DINDIGUL, No1, 2010. 
3) Vinay Kumar C. Jadhav, Rahulkumar M. Sonarand Santosh D. Sancheti Paper Published On FEA of Titanium Helical Gear Set, International Journal of Modern Trends in Engineering and Research-ISSN No.:2349-9745, Date: 28-30 April, 2016.

4) Chetan E. Kolambe and Dhananjay R. BardePaper Published On Study of Helical Gear Analysis Using FEA Software, DOI 10.4010/2016.517 ISSN 2321 3361, 2016IJESC

5) J. Venkatesh and Mr. P. B. G. S. N. Murthy Paper Published On Design and Structural Analysis of High Speed Helical Gear Using Ansys, Int. Journal of Engineering Research and Applications, ISSN: 2248-9622, Vol. 4, Issue 3(Version 2), March 2014, Pp.01-05

6) MO hit Singh, Wares Khan and Sanjeev Kumar Paper Published On Structural Analysis of Composite Material Helical Gear Under Different Loading Condition, International Journal of Engineering Sciences \& Research Technology, Singh* Et Al.,5. (6): June-2016, Doi: 10.5281/Zenodo.55629.
7) Modi Prashant ${ }^{1}$ Paper Published On Design and Analysis of Helical Gear Using Ansys, Fem \&Agma, International Research Journal of Engineering and Technology (IRJET), e-ISSN: 2395 -0056, Volume: 04 Issue: 01-Jan -2017

8) S. K. Suresh Kumarand S. Navaneethan Paper Published On Contact Stress Analysis of Helical Gear Pairs of Different Helix Angle, International Journal of Advanced Research in, ISSN: 22786252, Engineering and Applied Sciences Impact Factor: 5.795.

9) Machine Design by R.S. Khurmi

10) Handbook of Gear Design byMaitra

11) Handbook Of Practical Gear Design By Darle W. Dudley

12) Design Of Machine Elements By Bhandari 